\title{
The impact of primary healthcare reform on equity of utilization of services in the province of Quebec: a 2003-2010 follow-up
}

Marie-Jo Ouimet ${ }^{1 *}$, Raynald Pineault ${ }^{1}$, Alexandre Prud'homme' ${ }^{1}$, Sylvie Provost ${ }^{1}$, Michel Fournier ${ }^{1}$ and Jean-Frédéric Levesque ${ }^{2,3}$

\begin{abstract}
Introduction: In 2003, the Quebec government made important changes in its primary healthcare (PHC) system. This reform included the creation of new models of PHC, Family Medicine Groups (e.g. multidisciplinary health teams with extended opening hours and enrolment of patients) and Network Clinics (clinics providing access to investigation and specialist services). Considering that equity is one of the guiding principles of the Quebec health system, our objectives are to assess the impact of the PHC reform on equity by examining the association between socio-economic status (SES) and utilization of healthcare services between 2003 and 2010; and to determine how the organizational model of PHC facilities impacts utilization of services according to SES.

Methods: We held population surveys in $2005(n=9206)$ and $2010(n=9180)$ in the two most populated regions of Quebec province, relating to utilization and experience of care during the preceding two years, as well as organizational surveys of all PHC facilities. We performed multiple logistical regression analyses comparing levels of SES for different utilization variables, controlling for morbidity and perceived health; we repeated the analyses, this time including type of PHC facility (older vs newer models).

Results: Compared with the lowest SES, highest SES is associated with less emergency room visits (OR 0.80) and higher likelihood of at least one visit to a PHC facility (OR 2.17), but lower likelihood of frequent visits to PHC (OR 0.69), and higher affiliation to a family doctor (OR 2.04). Differences remained stable between the 2005 and 2010 samples except for likelihood of visit to PHC source which deteriorated for the lowest SES. Greater improvement in affiliation to family doctor was seen for the lowest SES in older models of PHC organizations, but a deterioration was seen for that same group in newer models.

Conclusions: Differences favoring the rich in affiliation to family doctor and likelihood of visit to PHC facility likely represent inequities in access to PHC which remained stable or deteriorated after the reform. New models of PHC organizations do not appear to have improved equity. We believe that an equity-focused approach is needed in order to address persisting inequities.
\end{abstract}

Keywords: Equity, Primary care, Primary healthcare, Utilization of services, Health disparities, Healthcare reform, Primary healthcare organization, Family practice

\footnotetext{
* Correspondence: mouimet@santepub-mtl.qc.ca

'Direction de la santé publique du CIUSSS du Centre-Sud-de-l'Île-de-Montréal,

1301 Sherbrooke est, Montréal, Québec H2L 1M3, Canada

Full list of author information is available at the end of the article
} 


\section{Résumé}

Introduction: En 2003, le gouvernement du Québec a instauré une réforme des services de santé de première ligne (SPL) qui s'est traduite principalement par la création des groupes de médecine de famille (équipes de soins multidisciplinaires avec heures d'ouverture étendues et inscription de patients) et des cliniques-réseau (permettant un meilleur accès aux plateaux techniques et aux spécialistes). L'équité étant l'un des principes centraux du système de santé québécois, nous nous proposons d'évaluer l'impact de la réforme des SPL sur l'équité en examinant l'association entre le statut socio-économique (SSE) et l'utilisation des services de santé entre 2003 et 2010 ainsi que l'impact des modèles d'organisation de services de SPL sur cette association.

Méthodologie: Nous avons mené une enquête téléphonique en $2005(n=9206)$ et $2010(n=9180)$ dans les deux régions les plus peuplées du Québec, portant sur l'utilisation des services de santé durant les deux années précédentes, ainsi qu'une enquête organisationnelle de toutes les organisations de SPL. Nous avons réalisé des analyses de régression logistique multivariée en comparant les niveaux de SSE selon diverses variables d'utilisation, en contrôlant pour la morbidité et la santé perçue; nous avons répété les analyses en incluant le type d'organisation de SPL (anciens vs nouveaux modèles).

Résultats: Comparativement au plus faible SSE, le SSE le plus élevé est associé à une probabilité moindre de visite à I'urgence (RC 0,80) et une probabilité plus élevée d'au moins une visite en SPL (RC 2,17), mais une probabilité moindre de visites fréquentes en SPL (RC 0,69) et une affiliation plus élevée à un médecin de famille (RC 2,04). Ces différences demeurent stables entre 2005 et 2010 sauf pour la probabilité d'au moins une visite en SPL qui s'est détériorée pour le plus faible SSE. L'affiliation au médecin de famille a davantage augmenté pour le SSE le plus faible dans les anciens modèles, mais elle a connu une plus grande détérioration pour ce même groupe dans les nouveaux modèles.

Conclusions: Les différences observées en faveur des riches représentent vraisemblablement des iniquités d'accès à la première ligne qui sont demeurées stables ou se sont détériorées après la réforme. Les nouveaux modèles de SPL ne semblent pas avoir amélioré l'équité. Une approche centrée sur l'équité apparait nécessaire pour réduire les iniquités persistantes.

\section{Introduction}

Access to healthcare and socio-economic status (SES) are well-known determinants of health [1]. The link between these two determinants of health has found growing interest in recent years $[2,3]$. Although universal healthcare systems aim to provide healthcare services according to need rather than ability to pay, in OECD countries, and in Canada in particular, it has been shown that access varies greatly and that utilization of services is not merely distributed according to need [2, 4-6]. Important factors involved are levels of income as well as education, social support and region of residence [7].

Inequities refer to differences that are judged unjust or unfair [8-10]. Although use of specialist services almost systematically shows a pro-rich distribution [11, 12], most industrialised countries with a universal health system have improved equity in the use of primary care services: in general, people with greater needs receive more primary care services [13]. But some degree of inequity still remains, such as pro-rich inequity in the number of visits to general practitioners (GP) for several European countries [11], fewer visits to the GP by people of lower SES in several OECD countries including Canada $[2,12]$, and pro-rich inequity in the probability of a GP visit in most Canadian provinces [6]. Some authors have even suggested that in recent years, inequities in utilization of primary care services may have appeared or increased $[11,12]$ in several European countries. Even though inequity in utilization is not strictly synonymous with unfairness in accessibility, as utilization is also dependent on individual preferences, need for care, expected benefit of care, as well as ability to seek care and to engage in the process of care $[6,14]$, looking at utilization as a proxy for accessibility is a widespread practice $[7,15]$. Also, not all inequalities or inequities in health can be solved by improved accessibility for those more in need of services. Action on other social determinants of health often plays a key role [16].

As mentioned above $[2,6]$, evidence suggests that there are persisting inequities in healthcare use in Canada, which is provided by provincial governments and is covered universally for hospital and physician services in all provinces. Equity is one of the guiding principles of the Quebec Health and social services system, which aims to ensure equitable access to quality care and services for all citizens [17]. This translates into policies aiming to facilitate access to healthcare in order to match utilization with health needs, especially for vulnerable populations. Differences exist between provinces in coverage for medication, as well as paramedical services such as psychotherapy, dentistry or physiotherapy; the province of Quebec, historically known to be one of Canada's most social-democratic 
provinces, offers the most thorough, though still incomplete, coverage for these.

Traditionally, Quebec PHC organizations have been divided into privately-owned clinics such as solo and group practices, where few other professionals are involved and opening hours vary greatly. Local community services centers (LCSC) are public clinics that were created in the early 1970s to provide health and social services. They are the most involved for socially vulnerable populations. LCSCs include a large proportion of nurses, social workers and psychologists, but their populational impact is very small as few patients are followed. Finally, family medicine units (FMU) are teaching units which share most characteristics of LCSCs.

In 2003 the Quebec government launched a reform, introducing Health and Social Services Centers (HSSC), local structures responsible for the coordination of all healthcare services in one specific geographical area and entrusted to form Local Health and Social Services Networks (LHSSN). The reform included the creation of new models of primary care that resulted from the transformation of the above-mentioned older models (LCSC, solo practice, group practice). The first model is the family medicine group (FMG) $[18,19]$. An FMG consists of 6 to 10 physicians who work consistently with nurses, and often other professionals (dieticians, psychologists and/or social workers), to provide services to enrolled patients on a non-geographical basis $(10,000$ to 20,000 patients per FMG). It offers increased accessibility through extended opening hours and participation in a regional on-call system (Table 1). In addition, under the initiative of Montreal Regional Health Agency, a complementary model of PHC organizations was implemented, the Network clinic (NC). A NC is more specifically aimed to improve accessibility through walk-in visits and provides better access to technical support, such as X-rays and laboratory tests, and to specialists. The distinction between FMG and NC is often difficult to establish, as many clinics have acquired both status, and thus benefit from two sources of funding, provincial and regional.

Through the creation of these new structures, the Quebec reform aimed to improve access and continuity in healthcare, as well as improve coordination of services [20]; this has been the object of formal evaluations [21-24]. There is growing literature linking access to healthcare with the models of organization of PHC $[18,19]$. Some studies link organizations such as FMGs to better accessibility of services [23]. However, although the concern for equity has been explicitly voiced by governmental bodies [20], no formal evaluation of the equity implications of the Quebec reform has been undertaken to this day. One would expect a reduction in inequalities due to the longstanding equity tradition of Quebec, but the literature on structural reforms and their impact on equity, though scarce, suggests that the opposite may occur in some contexts [25].

This paper is part of a project that aimed to follow the evolution of PHC models and its impact on patients' experience of care [26]. The main goal of the project was to identify models of $\mathrm{PHC}$ which are most adapted to the needs of the population, in order to inform clinicians and policymakers on the effects of the reform. The objective of this specific study is to examine the association between SES and utilization of healthcare services and its evolution between 2003 and 2010 in Quebec, and secondarily, to explore how organizational models of PHC (newer vs older) might impact utilization of services according to SES.

\section{Methods}

\section{Study design}

This study follows a longitudinal strategy with a natural experiment design without a control group, comparing two repeated independent samples of the population, in 2005 and 2010, and repeating a survey of all PHC organizations during the same time period.

\section{Data source}

The project consisted in two population-based telephone surveys of randomly-selected adults from the two most populous regions in the province of Quebec, Montréal and Montérégie. Using the random-digit dialing method, approximately 400 respondents were recruited in each of 23 local networks, for a total of 9206 respondents in the 2005 sample (response rate of $64 \%$ ). The survey was repeated in 2010 with 9180 respondents (response rate of $56 \%)$. Special attention was given to optimize response rates by the firm involved in the survey: many calls (maximum 140, mean 8.4) were made for each phone number; an alternative web-based questionnaire was offered to respondents who had refused the phone interview [27, 28].

The first survey provided a reference point for further comparison, as most elements of the reform were only partially implemented in 2005 [29-32], and questions referred to the two years preceding the survey. The survey allowed to assess the evolution of population-level experience of care up to seven years into the reform. The questionnaire covered demographic characteristics, income, education, morbidity, perceived health, as well as several questions relating to healthcare utilization and experience of care during the previous two years (see Additional file 1). Respondents who did not speak French or English were excluded, as well as those with significant disability interfering with the survey process.

Health services utilization was established by asking participants if they were affiliated with a family physician; if they had visited a family physician in the past two years, and if so, how often; if they had visited an emergency 
Table 1 Percentage of PHC organizations with specific organizational characteristics by type, 2005 and 2010

\begin{tabular}{|c|c|c|c|c|c|c|c|c|c|c|c|c|c|}
\hline \multirow{2}{*}{\multicolumn{2}{|c|}{ Organizational characteristics }} & \multirow{2}{*}{$\begin{array}{l}\text { FMG-NCa } \\
(N=16) \\
2005(\%)\end{array}$} & \multirow{2}{*}{2010 (\%) } & \multirow{2}{*}{$\begin{array}{l}F_{M G}^{b} \\
(N=86) \\
2005(\%)\end{array}$} & \multirow[b]{2}{*}{$2010(\%)$} & \multirow{2}{*}{$\begin{array}{l}N C^{C} \\
(N=17) \\
2005(\%)\end{array}$} & \multirow[b]{2}{*}{$2010(\%)$} & \multirow{2}{*}{$\begin{array}{l}\operatorname{LCSC}^{\mathrm{d}, \mathrm{e}} \\
(N=40) \\
2005(\%)\end{array}$} & \multirow[b]{2}{*}{$2010(\%)$} & \multicolumn{2}{|c|}{$\begin{array}{l}\text { Group practice } \\
(N=208)\end{array}$} & \multicolumn{2}{|c|}{$\begin{array}{l}\text { Solo practice } \\
(N=172)\end{array}$} \\
\hline & & & & & & & & & & $2005(\%)$ & $2010(\%)$ & $2005(\%)$ & $2010(\%)$ \\
\hline Presence of nurses & Yes & 77.8 & 100 & 66.3 & 83.7 & 70.6 & 94.1 & 97.5 & 97.5 & 23.1 & 27.9 & 13.4 & 18.6 \\
\hline $\begin{array}{l}\text { Presence of specialists and/or other health } \\
\text { professionals in the same building }\end{array}$ & Yes & 88.9 & 100 & 90.7 & 79.0 & 94.1 & 88.2 & 85.0 & 90.0 & 86.6 & 76.4 & 58.2 & 44.1 \\
\hline $\begin{array}{l}\text { Information technologies used } \\
\text { in the practice }\end{array}$ & At least one & 83.3 & 94.4 & 81.4 & 90.7 & 70.6 & 100 & 92.5 & 97.5 & 55.8 & 66.3 & 33.1 & 43.6 \\
\hline Collaboration with other PHC practices & Yes & 27.8 & 66.7 & 61.6 & 80.2 & 76.5 & 76.5 & 32.5 & 42.5 & 42.3 & 22.6 & 41.3 & 24.4 \\
\hline Collaboration with hospitals & Yes & 50.0 & 94.4 & 61.6 & 74.4 & 64.7 & 76.5 & 57.5 & 72.5 & 44.2 & 37.5 & 40.1 & 27.3 \\
\hline $\begin{array}{l}\text { Opened on evenings (after } 6 \text { PM) and } \\
\text { week-ends }\end{array}$ & Yes & 88.9 & 88.9 & 81.4 & 80.2 & 100 & 94.1 & 80.0 & 75.0 & 69.2 & 48.6 & 49.4 & 36.0 \\
\hline \multirow[t]{3}{*}{ Predominant type of visits in the practice } & Walk-in visits ${ }^{f}$ & 33.3 & 16.7 & 14.0 & 2.3 & 64.7 & 41.2 & 7.5 & 7.5 & 29.3 & 19.2 & 10.5 & 8.7 \\
\hline & By-appointment visits ${ }^{g}$ & 22.2 & 11.1 & 62.8 & 57.0 & 5.9 & 5.9 & 77.5 & 77.5 & 51.9 & 58.7 & 81.4 & 83.1 \\
\hline & Mixed $^{\text {h }}$ & 44.4 & 72.2 & 23.3 & 40.7 & 29.4 & 52.9 & 15.0 & 15.0 & 18.8 & 22.1 & 8.1 & 8.1 \\
\hline
\end{tabular}

${ }^{a}$ Family Medicine Group and Network Clinic (double status)

${ }^{\mathrm{b}}$ Family Medicine Group only

cNetwork Clinic only

dLocal Community Services Centre

eWithout FMG or NC status

$\mathrm{f}_{>50} \%$ of all visits are walk-in visits

$g_{\geq 75 \% \text { of all visits are by-appointment visits }}$

h 26 to $50 \%$ of all visits are walk-in visits 
room in the past two years; and if they had been hospitalized in the past two years. Those who had visited a family physician were asked to identify their main source of PHC. Even though our focus was on PHC, emergency room (ER) use and hospitalization were assessed because they are considered sensitive to access of PHC: better access to PHC is associated with lower use of ER and hospitalization rates [33].

In recent years, wealth has been thought to uncover a qualitatively different pattern of inequality that may be concealed by traditional measures of economic status such as income [34]. Moreover, it has been suggested to include other measures of economic status to income level to form a more accurate and balanced picture when using survey methodology $[35,36]$. Therefore, rather than using income as our only economic status indicator, we constructed a composite index combining annual crude income adjusted to size of household (divided into quartiles), perception of economic status (range: poor to well-off) and number of assets (car, house, savings), using a formative approach [37-41]. We refer to this index as SES even though education, which is often part of such indicators, is used as a separate variable in our models; using economic status alone as an indicator of SES is a commonly used approach [42]. Our index has since been widely used by our research team [43]. Each item is intended to represent a distinct conceptual dimension of SES, which is confirmed by the fact that items are not highly correlated with each other. Values of SES range from zero to ten. The score was divided according to groups that were evident in the distribution into four categories as follows: 0 to 3.6: very low SES; 4.6 to 6.4: low; 7.3 to 8.2: high; 9.1 to 10 : very high.

A composite index of morbidity was computed using self-reported numbers of cardiovascular risk factors (hypertension, diabetes, dyslipidemia) and numbers of chronic diseases (asthma/chronic obstructive pulmonary disease (COPD)/other respiratory illness, coronary artery disease (CAD)/heart failure/other cardiac illness, arthritis, stroke). Again, a formative approach was used. In most comparable surveys, morbidity is measured by computing the number of chronic diseases cumulated by an individual. Our measure is similar though it also includes a number of cardiovascular risk factors. This index was then divided into four sub-categories. Again, this index has been widely used by the research team $[26,31,32,43]$ and has been shown to predict hospitalization and ER use.

In addition to our morbidity index, we included perceived health as a separate health status variable, as it is often used as a complement to diagnosed illness in studies on healthcare utilization [44, 45].

All population-level data were weighted by attributing subjects the inverse probability of selection, in order to account for unequal sampling probabilities resulting from both local area sampling and intrahousehold selection. In addition, a post-stratification weighting comparing with census data was applied for age and sex distribution.

The project also included two surveys of PHC organizations which were conducted in 2005 and 2010 in the two same regions (see Additional file 2). A questionnaire was mailed to key informants in all PHC organizations of both Montréal and Montérégie. Questions related to vision, structure, resources and practices of the various sources of PHC [26]. The types of PHC sources existing in administrative databases as well as these organizational surveys can be divided as follows: family medicine groups (FMG), network clinics (NC), clinics having both FMG and NC status (FMG-NC), local community services centres (LCSC without FMG/NC status), family medicine teaching units (FMU without FMG/NC status), group clinics (involving more than one physician - not FMG/NC) and solo clinics (involving only one physician).

\section{Data analysis}

We first examined the association of SES with different outcomes representing utilization of health services, while controlling for socio-demographic and health status variables (detailed below), for both survey years (2005 and 2010). We tested all relevant variables according to our conceptual framework [46] (Fig. 1), within the limitations of available data. We selected variables that were statistically significantly associated with at least one outcome in bivariate analysis and performed multiple logistical analyses using STATA version 10.0 with all respondents $(n=18386)$ using the variables below. Analyses were made for 2005 and 2010 jointly, and interaction terms between year and SES were created in order to detect differential responses between economic groups. Need variables (morbidity and perceived health) were modelled as mediator variables in our final models, as shown in our conceptual framework $[45,46]$.

\section{1st objective: variables}

Outcome variables (utilization): "at least one hospitalization in past two years" (yes-no), "at least one visit to ER in past two years" (yes-no), "affiliation to a family doctor" (yes-no), "at least one visit to PHC source in past two years" (yes-no).

Control variables (predisposing factors): age, sex, level of education, ${ }^{1}$ immigration status (born in Canada, immigrated to Canada less than 10 years ago, immigrated to Canada 10 years ago or more).

Mediator variables (needs): morbidity level (no cardiovascular risk factor ${ }^{2}$ or chronic disease, ${ }^{3}$ at least one cardiovascular risk factor, one chronic disease with/without risk factor, at least two chronic diseases with/without 


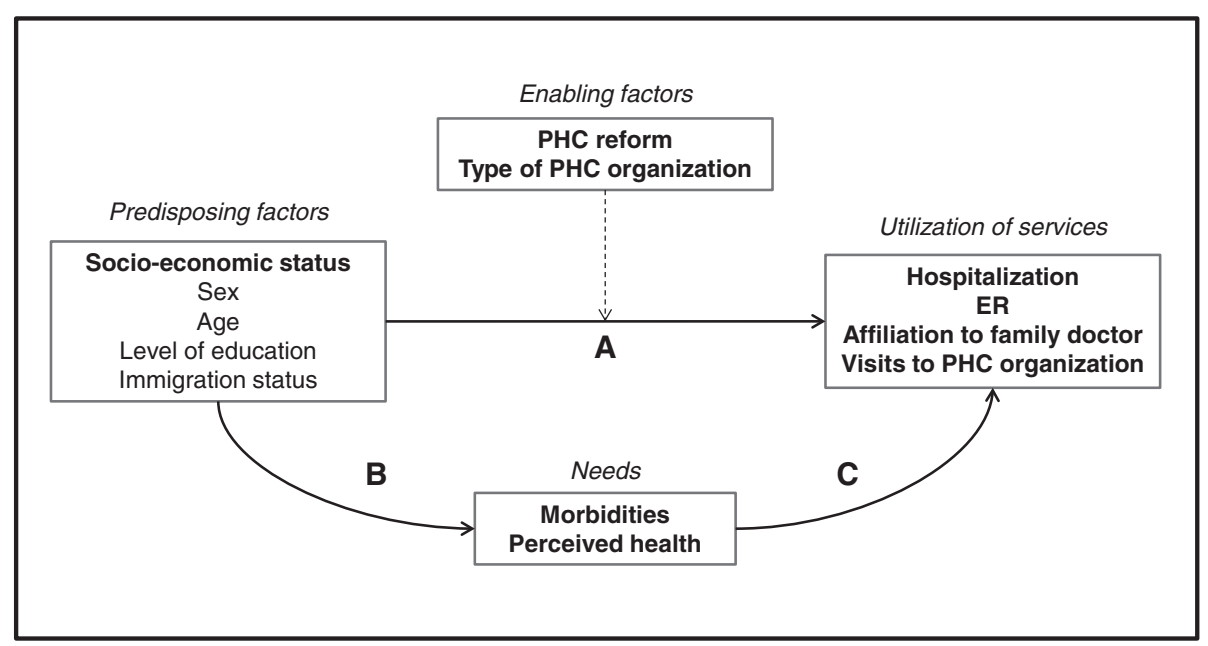

Fig. 1 Conceptual framework

risk factor), perceived health (poor/average, good, very good, excellent).

Predictors (predisposing/enabling factors): year (2005 or 2010), SES (very low, low, high, very high).

Interaction variables: year $\times$ SES.

In order to address our second objective, i.e. how the pre- vs post-reform organizational model of PHC might impact utilization of services according to SES, we repeated the above analyses but this time we introduced the type of PHC source in our model. All six previously mentioned categories of PHC sources were separated into two broad types: older models (LCSC/FMU, group clinic, solo clinic) and newer models (FMG, NC, blended model (FMG-NC)). Interaction terms between year and SES were maintained, and new interaction terms between year, type of PHC and SES were added in order to detect differential responses between these three variables.

\section{2nd objective: variables}

Outcome variables (utilization): "at least one hospitalization in past two years" (yes-no), "at least one visit to ER in past two years" (yes-no), "affiliation to a family doctor" (yes-no).

Control variables (predisposing factors): age, sex, level of education, immigration status (born in Canada, immigrated to Canada less than 10 years ago, immigrated to Canada 10 years ago or more).

Mediator variables (needs): morbidity level (no cardiovascular risk factor $^{2}$ or chronic disease ${ }^{3}$, at least one cardiovascular risk factor, one chronic disease with/without risk factor, at least two chronic diseases with/without risk factor), perceived health (poor/average, good, very good, excellent).
Predictors (predisposing/enabling factors): year (2005 or 2010), SES (very low, low, high, very high), type of PHC (older model, newer model).

Interaction terms: year $\times \mathrm{SES}$, year $\times$ type of $\mathrm{PHC}$, SES $\times$ type of PHC, SES $\times$ year $\times$ type of PHC.

For these analyses, only respondents who had declared a PHC source were included $(n=12951)$. Outcome variables therefore did not include "at least one visit to PHC source" as this was the criterion to define users of a PHC source. The analyses were performed using the 2010 type and comparing results for the same clinics in time; for example, a clinic that had become a $\mathrm{NC}$ in 2010 was included in the NC group in 2005.

Finally, we analyzed the association of SES with frequency of utilization of PHC using the following outcome variable for users of PHC services only $(n=12951)$ : "at least six visits to PHC source during the past two years" (yes-no). There is no consensus in the literature about the definition of frequent users of PHC [47]. Some authors choose a number of visits [48], while others prefer to establish a threshold in the distribution in order to allow better comparison between settings [49]. Limitations related to our questionnaire (see Additional file 1) and distribution of our data pointed towards a cut-off point of 6 visits. Additional analyses using different thresholds (available from the authors upon request) led to the same conclusion. Again, all other variables remained the same, and analyses were performed with and without the variable " type of PHC" in our model.

For all analyses, odds ratios (OR) with their $95 \%$ confidence intervals $(\mathrm{CI})$ were computed. Where interaction terms were shown significant, adjusted probabilities were calculated and schematized. As mentioned above, all analyses were weighted to account for unequal probabilities 
of sampling which arise from the stratified two-stage sampling as well as for age and sex distribution.

\section{Ethics approval}

Our study was performed in accordance with the principles of the Helsinki Declaration. The Research Ethics Committee of the "Agence de la santé et des services sociaux de Montréal" gave approval for the study.

\section{Results}

Demographic information on the 2005 and 2010 samples is shown in Table 2. Based on census data, the 2005 sample was representative of the general population with regard to all variables except level of education. The 2010 sample differed significantly from the 2005 sample, as more respondents were in the higher education categories. Proportions of respondents in the low and high

Table 2 Characteristics of respondents (2005: $n=9206$; 2010: $n=9180)$ (weighted samples)

\begin{tabular}{|c|c|c|c|c|}
\hline \multicolumn{2}{|l|}{ Subject characteristics } & \multirow{2}{*}{$\begin{array}{c}2005(\%) \\
48.5\end{array}$} & \multirow{2}{*}{$\begin{array}{c}2010(\%) \\
48.7\end{array}$} & \multirow{2}{*}{$\frac{p \text { (Chi-2) }}{.783}$} \\
\hline Sex & M & & & \\
\hline \multirow[t]{4}{*}{ Age } & $18-29$ & 20.6 & 19.7 & .031 \\
\hline & $30-44$ & 28.4 & 27.2 & \\
\hline & $45-64$ & 33.5 & 34.6 & \\
\hline & $65+$ & 17.5 & 18.5 & \\
\hline \multirow[t]{4}{*}{ Level of education } & $<$ Secondary & 15.8 & 12.5 & $<.001$ \\
\hline & Secondary & 32.5 & 30.1 & \\
\hline & College & 24.2 & 20.8 & \\
\hline & University & 27.5 & 36.7 & \\
\hline \multirow[t]{4}{*}{$\mathrm{SES}^{\mathrm{a}}$} & Very low & 11.4 & 10.0 & $<.001$ \\
\hline & Low & 32.8 & 30.9 & \\
\hline & High & 29.9 & 32.6 & \\
\hline & Very high & 25.9 & 26.5 & \\
\hline \multirow[t]{3}{*}{ Immigrant status } & Born in Canada & 80.5 & 79.5 & .261 \\
\hline & $\begin{array}{l}\text { Has immigrated } \\
<10 \text { years }\end{array}$ & 6.3 & 6.6 & \\
\hline & $\begin{array}{l}\text { Has immigrated } \\
\geq 10 \text { years }\end{array}$ & 13.2 & 13.9 & \\
\hline \multirow[t]{4}{*}{ Morbidity } & None & 49.5 & 48.5 & .096 \\
\hline & $\geq 1$ risk factor ${ }^{b}$ & 16.8 & 18.0 & \\
\hline & 1 chr. disease ${ }^{c}$ & 25.6 & 25.9 & \\
\hline & $\geq 2 \mathrm{chr}$. diseases & 8.2 & 7.6 & \\
\hline \multirow[t]{4}{*}{ Perceived Health } & Poor or average & 16.3 & 14.6 & .001 \\
\hline & Good & 28.4 & 29.7 & \\
\hline & Very good & 34.7 & 34.0 & \\
\hline & Excellent & 20.5 & 21.8 & \\
\hline
\end{tabular}

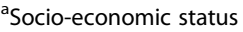

${ }^{b}$ Without chronic disease. Cardiovascular risk factors: hypertension, diabetes, dyslipidemia

${ }^{c}$ With/without risk factor. Chronic diseases: asthma/COPD/other respiratory

illness, CAD/heart failure/other cardiac illness, arthritis, stroke
SES also differed slightly between both years, as well as the age composition, which is slightly older in 2010. Table 3 shows the distribution of respondents according to the utilization variables for all levels of SES. Also included is the distribution of respondents according to variable "has a usual source of PHC" which is not included in subsequent models, for reference purposes only.

For all logistical regression analyses results, though results relating to control variables may be of interest, they will not be discussed as our focus is on SES.

Results of the analyses corresponding to our first objective, i.e. the association between SES and utilization of healthcare services, and its evolution between the 2005 and 2010 surveys, are shown in Table 4. For all levels of SES, whether tested together or separately, there is no significant difference between years 2005 and 2010 for likelihood of hospitalization.

Slightly different results apply to ER use (Table 4). Globally, there is no difference in likelihood of an ER visit between both sample years, but when taken separately, the low and very high SES are less likely to visit the ER than other levels of SES (low SES 0.82, CI 0.70-0.98; very high SES OR 0.80, CI 0.66-0.97). There is no evidence that the observed differences may have changed between the 2005 and 2010 samples, as interaction terms between year and SES are not significant.

Likelihood of affiliation to a family doctor is unchanged between the 2005 and 2010 samples globally. However, likelihood of affiliation increases concurrently with SES (low SES OR 1.46, CI 1.21-1.76; high SES OR 1.88, CI 1.56-2.29; very high SES OR 2.03, CI 1.65-2.51). Interactions between year and SES are again not significant. Thus, when we translate these results into adjusted probabilities, we find that in the 2005 sample, $59 \%$ of the very low SES people were affiliated to a family doctor, compared with $58 \%$ in 2010 (non significant). In contrast, $72 \%$ of the very high SES people were affiliated to a family physician in 2005, compared with $74 \%$ in 2010 (data available upon request).

Respondents of all SES levels combined are less likely to declare having visited a PHC source in 2010 than in 2005 (OR 0.69, CI 0.52-0.90). However, individuals in the high and very high SES are more likely to have visited a PHC source (high SES OR 1.81, CI1.43-2.29; very high SES OR 2.17, CI 1.67-2.81) than the very low SES. This time, interactions between year and SES are significant for the low and high SES, suggesting that observed differences between levels of SES have changed in 2010 compared with 2005 (Fig. 2). In fact, the gap has decreased between the three higher SES groups, but it has widened with the very low SES.

Analyses which included type of PHC source were restricted to respondents who had declared at least one visit to a PHC source, since respondents who had not 
Table 3 Distribution of respondents according to utilization of services, by SES, 2005 ( $n=9206)$ and 2010 ( $n=9180)$ (weighted samples)

\begin{tabular}{|c|c|c|c|c|c|c|c|c|c|c|c|}
\hline \multirow{2}{*}{\multicolumn{2}{|c|}{ Utilization variable }} & \multicolumn{2}{|l|}{ Very low } & \multicolumn{2}{|l|}{ Low } & \multicolumn{2}{|l|}{ High } & \multicolumn{2}{|l|}{ Very high } & \multicolumn{2}{|l|}{ Total } \\
\hline & & $2005(\%)$ & $2010(\%)$ & $2005(\%)$ & $2010(\%)$ & $2005(\%)$ & $2010(\%)$ & $2005(\%)$ & $2010(\%)$ & $2005(\%)$ & $2010(\%)$ \\
\hline \multicolumn{2}{|c|}{ Has a usual source of PHC } & 63.2 & 65.4 & 67.7 & 76.8 & 74.7 & 82.7 & 75.1 & 81.1 & 71.2 & 78.8 \\
\hline \multicolumn{2}{|c|}{$\geq 1$ hospitalization past 2 years } & 21.6 & 24.9 & 15.9 & 19.0 & 13.7 & 18.3 & 12.5 & 13.7 & 15.0 & 18.0 \\
\hline \multicolumn{2}{|c|}{$\geq 1$ ER visit past 2 years } & 37.9 & 40.1 & 31.9 & 38.5 & 30.8 & 32.5 & 27.1 & 31.8 & 31.0 & 34.9 \\
\hline \multicolumn{2}{|c|}{$\geq 1$ visit to $\mathrm{PHC}$ past 2 years } & 78.5 & 73.3 & 79.4 & 82.7 & 85.9 & 86.1 & 88.0 & 85.4 & 83.5 & 83.6 \\
\hline \multicolumn{2}{|c|}{$\geq 6$ visits to $\mathrm{PHC}$ past 2 years ${ }^{\mathrm{a}}$} & 30.7 & 27.0 & 26.5 & 22.6 & 20.5 & 17.1 & 15.9 & 12.9 & 22.2 & 18.4 \\
\hline \multirow[t]{8}{*}{ PHC type ${ }^{a}$} & FMG-NC & 9.7 & 12.8 & 9.8 & 10.4 & 9.7 & 10.7 & 10.8 & 12.4 & 10.0 & 11.2 \\
\hline & FMG & 21.4 & 21.5 & 26.4 & 26.2 & 27.3 & 27.6 & 25.5 & 26.4 & 25.9 & 26.3 \\
\hline & NC & 11.8 & 11.1 & 9.6 & 8.9 & 7.7 & 8.9 & 7.4 & 8.1 & 8.6 & 8.9 \\
\hline & Total newer models & 42.8 & 45.4 & 45.8 & 45.4 & 44.7 & 47.2 & 43.7 & 46.8 & 44.6 & 46.4 \\
\hline & LCSC & 9.9 & 9.7 & 7.6 & 6.7 & 6.0 & 3.5 & 5.1 & 4.7 & 6.6 & 5.3 \\
\hline & Group practice & 40.9 & 36.4 & 39.2 & 37.9 & 41.0 & 40.0 & 43.8 & 40.6 & 41.2 & 39.2 \\
\hline & Solo practice & 6.3 & 8.6 & 7.5 & 10.0 & 8.3 & 9.2 & 7.4 & 8.0 & 7.6 & 9.1 \\
\hline & Total older models & 57.2 & 54.6 & 54.2 & 54.6 & 55.3 & 52.8 & 56.3 & 53.2 & 55.4 & 53.6 \\
\hline \multicolumn{2}{|c|}{ Affiliation to family doctor } & 58.4 & 65.0 & 66.1 & 70.9 & 71.1 & 78.4 & 72.0 & 76.8 & 68.2 & 74.3 \\
\hline
\end{tabular}

${ }^{\mathrm{a}}$ Among individuals who have a usual source of PHC $\left(\mathrm{n}^{2005}=6198 ; \mathrm{n}^{2010}=6753\right)$

Table 4 Factors associated with utilization of services among all respondents in past two years ( $n=18386), 2005$ and 2010 samples combined (logistical regression)

\begin{tabular}{|c|c|c|c|c|c|c|c|c|c|c|c|c|c|}
\hline \multirow{3}{*}{$\begin{array}{l}\text { Variables in model } \\
\text { Year (ref.: 2005) }\end{array}$} & \multirow[b]{3}{*}{2010} & \multicolumn{3}{|c|}{ Hospitalization } & \multicolumn{3}{|l|}{ ER } & \multicolumn{3}{|c|}{ Affiliation to family doctor } & \multicolumn{3}{|c|}{$\geq 1$ visit to $\mathrm{PHC}$ past 2 years } \\
\hline & & \multirow{2}{*}{$\begin{array}{l}\mathrm{OR} \\
1.257\end{array}$} & \multicolumn{2}{|c|}{$95 \% \mathrm{Cl}$} & \multirow{2}{*}{$\frac{\mathrm{OR}}{1.141}$} & \multicolumn{2}{|c|}{$95 \% \mathrm{Cl}$} & \multirow{2}{*}{$\begin{array}{l}\text { OR } \\
.955\end{array}$} & \multicolumn{2}{|c|}{$95 \% \mathrm{Cl}$} & \multirow{2}{*}{$\begin{array}{l}\mathrm{OR} \\
.689\end{array}$} & \multicolumn{2}{|c|}{$95 \% \mathrm{Cl}$} \\
\hline & & & .981 & 1.610 & & .923 & 1.409 & & .747 & 1.222 & & .525 & .903 \\
\hline SES & Low & .806 & .652 & .995 & .824 & .695 & .978 & 1.460 & 1.212 & 1.758 & 1.118 & .898 & 1.391 \\
\hline \multirow[t]{2}{*}{ (ref.: Very low) } & High & .862 & .688 & 1.079 & .859 & .717 & 1.029 & 1.881 & 1.548 & 2.286 & 1.812 & 1.432 & 2.293 \\
\hline & Very high & .918 & .718 & 1.173 & .796 & .656 & .966 & 2.035 & 1.650 & 2.511 & 2.168 & 1.667 & 2.819 \\
\hline Interaction year $\times$ SES & Low $\times 2010$ & 1.044 & .772 & 1.411 & 1.216 & .945 & 1.565 & 1.064 & .797 & 1.422 & 1.799 & 1.301 & 2.489 \\
\hline \multirow[t]{2}{*}{ (ref:: Very low x 2010) } & High $\times 2010$ & 1.163 & .857 & 1.578 & 1.003 & .778 & 1.292 & 1.227 & .918 & 1.640 & 1.408 & 1.009 & 1.963 \\
\hline & Very high $\times 2010$ & .931 & .671 & 1.293 & 1.132 & .867 & 1.477 & 1.167 & .863 & 1.577 & 1.190 & .837 & 1.694 \\
\hline Sex (ref:: Male) & Female & 1.387 & 1.250 & 1.540 & .955 & .882 & 1.035 & 1.837 & 1.684 & 2.004 & 2.319 & 2.086 & 2.578 \\
\hline Age & $30-44$ & .935 & .795 & 1.099 & .828 & .732 & .937 & 1.458 & 1.288 & 1.651 & 1.197 & 1.029 & 1.392 \\
\hline \multirow[t]{2}{*}{ (ref:: 18-29) } & $45-64$ & .652 & .552 & .771 & .548 & .483 & .622 & 2.591 & 2.277 & 2.949 & 1.214 & 1.038 & 1.421 \\
\hline & 65 or over & .895 & .742 & 1.081 & .445 & .382 & .519 & 5.137 & 4.286 & 6.158 & 1.168 & .953 & 1.432 \\
\hline Level of education & Secondary & .814 & .698 & .948 & 1.003 & .881 & 1.142 & 1.029 & .882 & 1.200 & 1.181 & .997 & 1.401 \\
\hline \multirow[t]{2}{*}{ (ref.: <Secondary) } & College & .771 & .649 & .916 & .981 & .849 & 1.133 & .924 & .784 & 1.091 & 1.466 & 1.208 & 1.778 \\
\hline & University & .729 & .616 & .864 & .892 & .774 & 1.027 & .873 & .741 & 1.028 & 1.446 & 1.200 & 1.743 \\
\hline Immigrant status & $\begin{array}{l}\text { Has immigrated } \\
<10 \text { years }\end{array}$ & .893 & .704 & 1.133 & .718 & .600 & .860 & .524 & .435 & .632 & .646 & .528 & .789 \\
\hline (ref.: Born in Canada) & $\begin{array}{l}\text { Has immigrated } \\
\geq 10 \text { years }\end{array}$ & 1.013 & .866 & 1.184 & 1.064 & .945 & 1.198 & .977 & .855 & 1.115 & .970 & .824 & 1.142 \\
\hline Morbidity & $\geq 1$ risk factor & 1.159 & .991 & 1.355 & 1.094 & .974 & 1.230 & 2.398 & 2.100 & 2.738 & 2.929 & 2.465 & 3.480 \\
\hline \multirow[t]{2}{*}{ (ref.: None) } & $1 \mathrm{chr}$. disease & 1.540 & 1.347 & 1.761 & 1.476 & 1.332 & 1.634 & 1.722 & 1.537 & 1.928 & 2.313 & 1.992 & 2.687 \\
\hline & $\geq 2 \mathrm{chr}$. diseases & 2.863 & 2.399 & 3.419 & 2.429 & 2.084 & 2.832 & 2.657 & 2.165 & 3.261 & 3.429 & 2.605 & 4.514 \\
\hline Perceived health & Good & .579 & .507 & .663 & .655 & .583 & .735 & 1.127 & .980 & 1.297 & .748 & .626 & .895 \\
\hline \multirow[t]{2}{*}{ (ref.: Poor/Average) } & Very good & .398 & .344 & .461 & .514 & .456 & .580 & 1.191 & 1.034 & 1.372 & .698 & .583 & .835 \\
\hline & Excellent & .383 & .322 & .455 & .425 & .369 & .489 & 1.133 & .970 & 1.324 & .533 & .441 & .644 \\
\hline
\end{tabular}




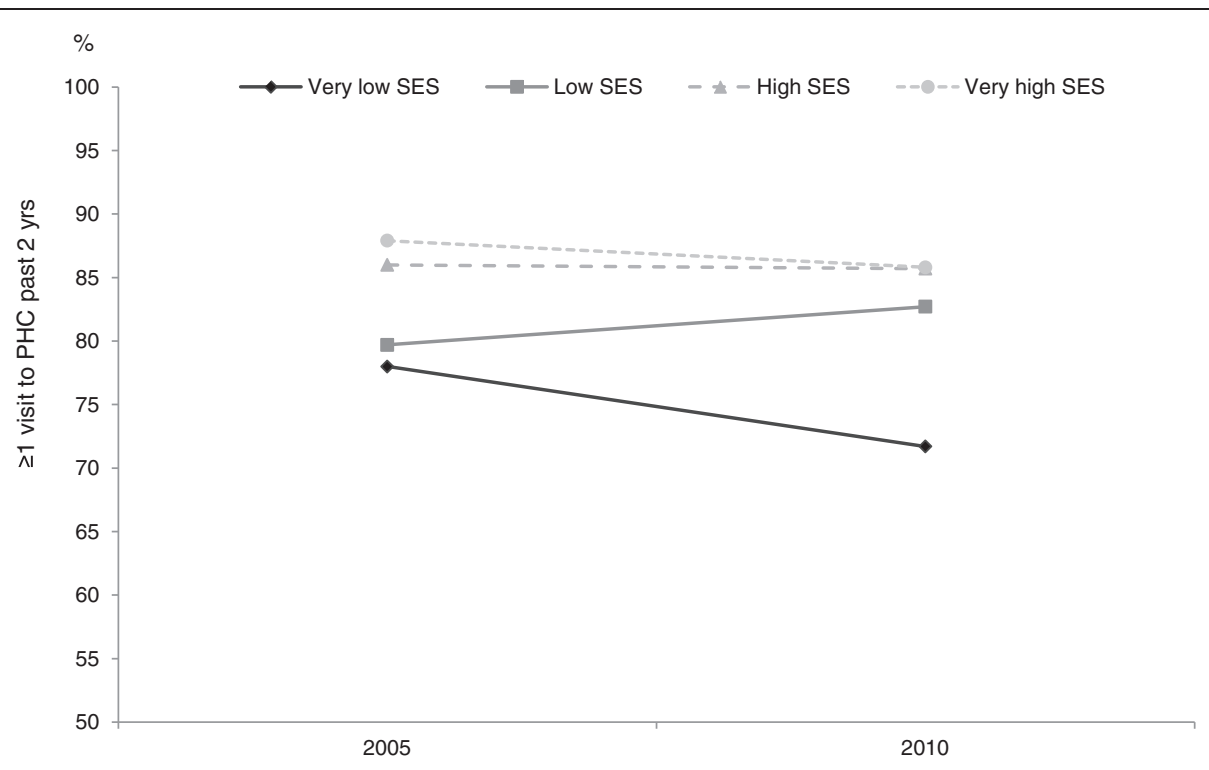

Fig. 2 Probability of at least one visit to PHC source in past two years according to socio-economic status

visited PHC could not be linked with a given source. Results for likelihood of hospitalization, ER use and frequency of use of PHC were comparable to results of analyses performed previously. However, there appears to be a differential relationship between year and SES when we examine adjusted probability of affiliation to a family doctor for old vs new types of PHC. This relationship is schematized in Fig. 3 (old models of PHC) and Fig. 4 (new models PHC). Affiliation to a family doctor appears to have improved between the 2005 and 2010 samples for the very low SES group more than for other groups within the old models; conversely, affiliation has deteriorated for the very low SES group in the new models whereas it has improved slightly for the other SES groups.

Finally, we examined the likelihood of having six or more visits to the PHC source among those respondents who had at least one visit to PHC (Table 5). We found no evidence that the likelihood of having six or more visits to PHC had changed between the 2005 and 2010 samples for all levels of SES combined. Likelihood of high frequency of use (six or more visits) decreased concurrently with SES but was only significant for the very high group (OR 0.69, CI 0.53-0.90). Observed

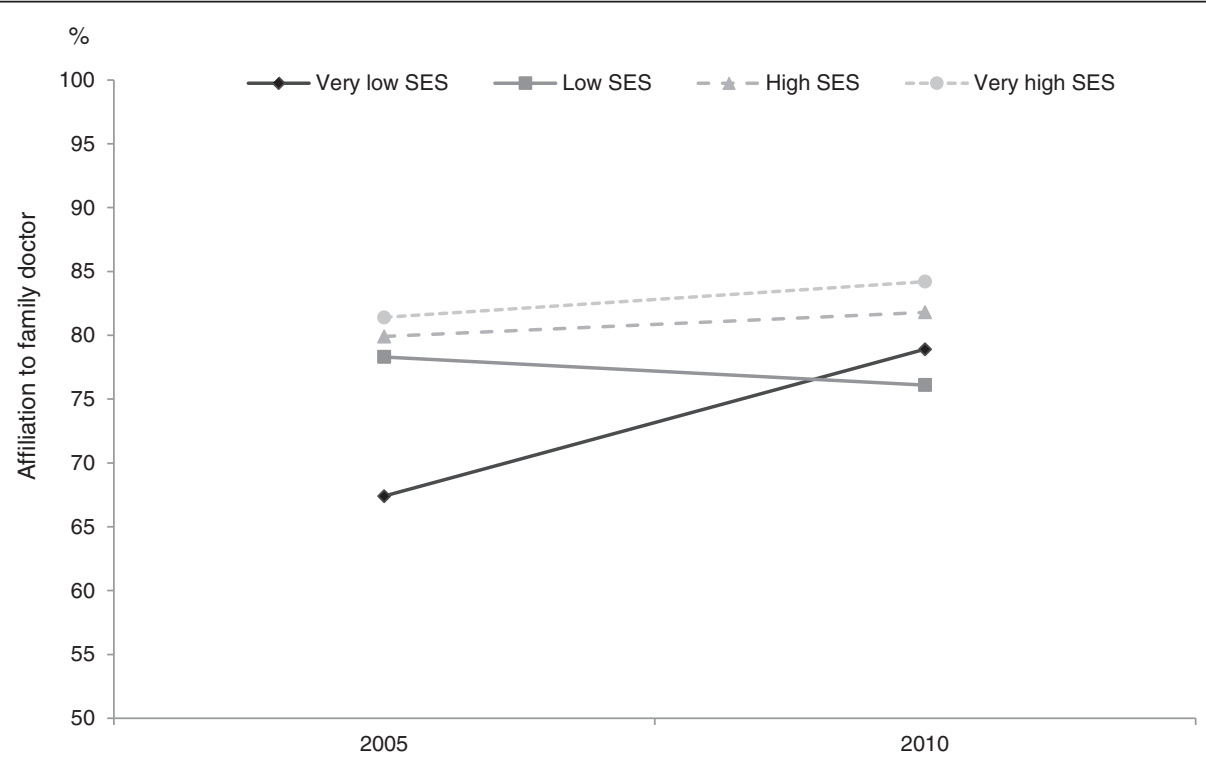

Fig. 3 Probability of affiliation to a family doctor according to socio-economic status (old models of PHC) 


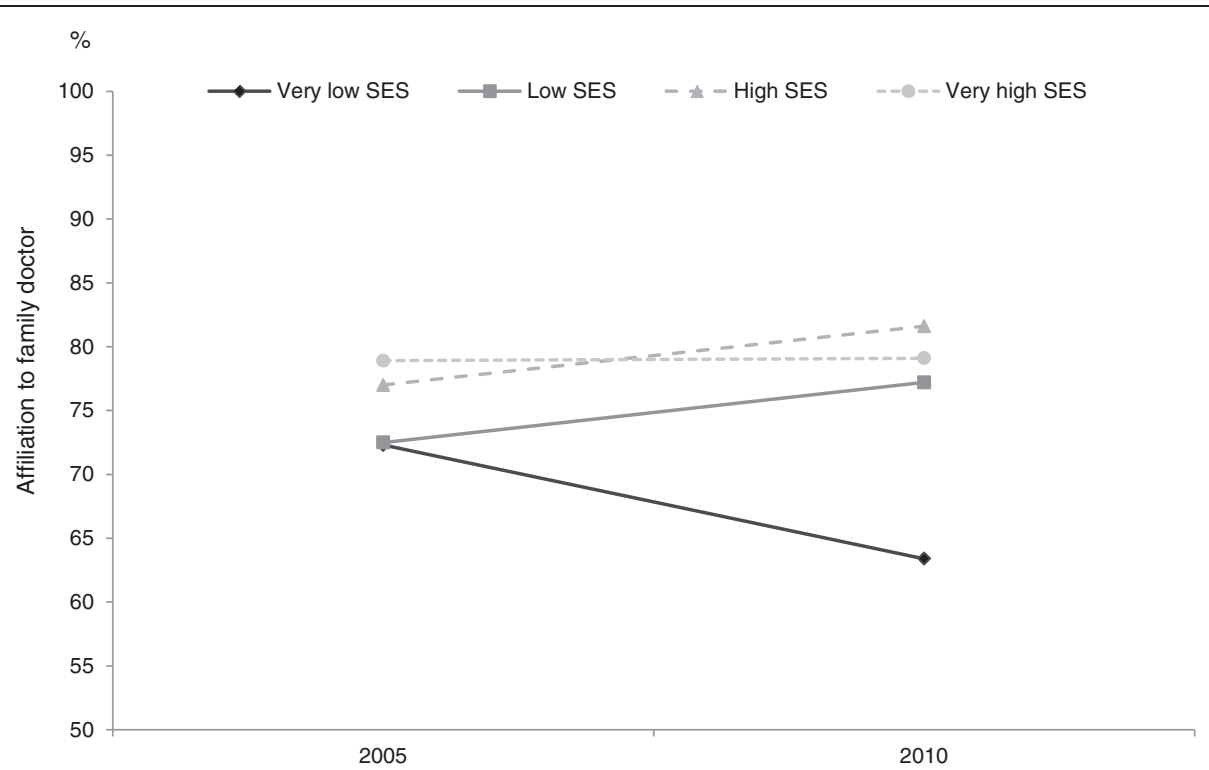

Fig. 4 Probability of affiliation to a family doctor according to socio-economic status (new models of PHC)

Table 5 Factors associated with high utilization ( $\geq 6$ visits) of PHC services among users in past two years $(n=12951), 2005$ and 2010 samples combined (logistical regression)

\begin{tabular}{|c|c|c|c|c|}
\hline \multicolumn{2}{|l|}{ Variables in model } & \multicolumn{3}{|c|}{$\geq 6$ visits to $\mathrm{PHC}$ past 2 years } \\
\hline & & \multirow{2}{*}{$\begin{array}{l}\mathrm{OR} \\
789\end{array}$} & \multicolumn{2}{|c|}{$95 \% \mathrm{Cl}$} \\
\hline Year (ref.: 2005) & 2010 & & .595 & 1.045 \\
\hline SES & Low & .923 & .727 & 1.173 \\
\hline \multirow[t]{2}{*}{ (ref:: Very low) } & High & .824 & .642 & 1.057 \\
\hline & Very high & .690 & .527 & .903 \\
\hline Interaction year $\times$ SES & Low $\times 2010$ & 1.042 & .743 & 1.461 \\
\hline \multirow[t]{2}{*}{ (ref.: Very low x2010) } & High $\times 2010$ & 1.005 & .715 & 1.412 \\
\hline & Very high x2010 & 1.094 & .756 & 1.581 \\
\hline Sex (ref.: Male) & Female & 1.365 & 1.218 & 1.530 \\
\hline Age & $30-44$ & .920 & .755 & 1.121 \\
\hline \multirow[t]{2}{*}{ (ref.: 18-29) } & $45-64$ & .846 & .700 & 1.024 \\
\hline & 65 or over & 1.031 & .834 & 1.276 \\
\hline Level of education & Secondary & .948 & .805 & 1.116 \\
\hline \multirow[t]{2}{*}{ (ref:: <Secondary) } & College & .749 & .624 & .900 \\
\hline & University & .752 & .626 & .903 \\
\hline Immigrant status & Has immigrated $<10$ years & .771 & .566 & 1.052 \\
\hline (ref.: Born in Canada) & Has immigrated $\geq 10$ years & .968 & .820 & 1.143 \\
\hline Morbidity & $\geq 1$ risk factor & 1.807 & 1.542 & 2.116 \\
\hline \multirow[t]{2}{*}{ (ref.: None) } & $1 \mathrm{chr}$. Disease & 1.773 & 1.532 & 2.051 \\
\hline & $\geq 2$ chr. diseases & 3.086 & 2.539 & 3.752 \\
\hline Perceived health & Good & .706 & .609 & .817 \\
\hline \multirow[t]{2}{*}{ (ref.: Bad/Average) } & Very good & .502 & .428 & .588 \\
\hline & Excellent & .337 & .273 & .415 \\
\hline
\end{tabular}


differences between SES groups remained stable between the 2005 and 2010 samples as interaction between year and SES was not significant. This time, including type of PHC source did not suggest a differential effect of type of PHC model on equity of utilization (data available upon request).

\section{Discussion}

Our results show differences in utilization of healthcare services between socio-economic groups. Higher SES people are less likely to visit the ER and be high-frequency users of PHC. These two utilization variables being closely related to one another, it is not surprising that results point in the same direction. Conversely, our results show that lower SES individuals are less likely to be affiliated to a family doctor, and also less likely to report at least one visit to a PHC source. Again, these two last variables are closely linked. All observed differences are stable between 2005 and 2010 except for likelihood of at least one visit to PHC source. For this last indicator, the situation seems to have improved in 2010 in favor of the low and high SES, but has deteriorated for the very low SES.

Our results suggest differences when we include type of PHC source: there appear to be observable differences in equity between older and newer models of PHC concerning affiliation to a family doctor. Inequities appear to have improved in the old models, and to have deteriorated in the new models.

Whether some of the observed differences in favor of the lowest SES actually translate into equity depends on an accurate measurement of need factors. In our study we included morbidity, but our measure was only partial, computing risk factors and chronic diseases but not their severity; perceived health may be a more accurate measure of severity of illness but again it is incomplete. Nevertheless, the higher likelihood of utilization by the disadvantaged could mean that equity exists for use of ER services and, to a lesser extent, frequency of use of PHC once PHC is accessed, considering that the poor have greater needs for services.

The differences in favor of the rich, observed in affiliation to a family doctor and likelihood of at least one visit to PHC source, suggest that there are inequities in accessing family physicians and PHC source, and that some of these inequities have worsened despite the PHC reform. The fact that in 2010, after controlling for other variables, $58 \%$ of people in the lowest SES category were affiliated to family doctors compared to $74 \%$ in the highest SES category is disturbing from a policy perspective. Even more disturbing is the fact that while for the high and very high SES, $86-87 \%$ of individuals visited a PHC source during both study periods, this proportion has fallen from 78 to $72 \%$ for the very low SES during the same period.
The results showing that affiliation to family physicians has remained stable for all SES groups in 2010, while likelihood of at least one visit to PHC has decreased (OR $0.69)$, suggest that affiliation to a family doctor does not necessarily equate with access to $\mathrm{PHC}$. The fact that more nurses were involved in PHC in 2010 could act as a confounding factor that our data could not control for.

More importantly, results suggesting that affiliation to family doctors improved for the very low SES group in old models of PHC, but deteriorated in the new models, seem to imply that the reform failed to improve equity of PHC delivery on that important aspect. Official registration with a family physician was first implemented in new models, which may mean that the registration process itself could lead to increased inequities in attributing patients to physicians.

Our analysis supports previous Canadian and international studies which suggested that removing financial barriers to healthcare is insufficient to ensure equity in utilization of services [2, 4-6, 50-54]. However, since the literature is relatively scarce about the equity implications of health reforms in countries with universal healthcare systems $[25,55]$ and methodologies differ significantly, it is difficult to make comparisons on that important aspect of our study.

The differences we have observed between SES levels for ER use cannot be explained only by higher disease prevalence since our analysis controls for a number of risk factors and chronic diseases; therefore we hypothesize that lower SES could be associated with delayed access, leading to health status deterioration and increased severity of disease (as discussed above, we did not have an accurate measure of severity of disease), which in turn would lead to higher use of ER services and, to a lesser extent, higher frequency of use of PHC source, as was also suggested by other authors [51, 56-58]. It is likely that individuals of higher SES are able to benefit more effectively from the healthcare system.

This would also explain why the disadvantage observed in likelihood of visit to PHC for the lowest SES has deteriorated; the complexity associated with all PHC structures, old and new, after the reform, may have played a role in this respect. A recent study performed in Quebec supports this hypothesis: complexity of the healthcare system was mentioned as one of the main barriers to seeking and benefitting from care for deprived individuals [59]. New financial barriers implemented during the study period such as administrative fees, although they are still not used consistently in the Quebec healthcare system, may have further widened the gap in utilization of PHC between the rich and the poor; unfortunately our data does not allow us to confirm this hypothesis. 
Poor health literacy $[58,59]$ could certainly make navigating through the healthcare system more challenging; this is particularly true about registration with a family physician, which is often perceived as a complex process. New structures may have become even more complex than the older ones, which could partly explain the differences we have observed between old and new PHC models. Also, the fact that affiliation to a family physician in Quebec is voluntary certainly needs to be questioned further when discussing the equity impacts of this reform. Although there are incentives for registering vulnerable populations with a GP, SES has not been considered a criterion for vulnerability by the Quebec healthcare system administrative rules. A rostering system in favor of the disadvantaged could help to complement other aspects of the reform in improving equity. In fact, the equity of attribution of patients through access registries has recently been questioned [60] and should be thoroughly examined for improvement. Complementary solutions recently suggested by the actual Quebec Ministry of Health, such as increasing the number of patients per family physician and widely adopting advanced access, while promising, need to be carefully planned and implemented with a concern for equity in order to improve rather than increase existing inequities.

Asada [5] suggests that processes involved in use versus frequency of use of services may differ. Frequency depends more on the professional's decision, often referred to as secondary demand for services, while use or non-use depends more on the individual's decision, also known as primary demand for care. That could explain why results for both variables do not point in the same direction.

Most importantly, we feel that our results support the conceptual framework for access to healthcare [14] which suggests that equity of access depends on a series of preliminary conditions in order for an individual to obtain and benefit from services: ability to perceive the need for, ability to seek and ability to reach services. In our study, we examined hospitalizations and ER use, which are highly dependent on need; affiliation to family physician and use of PHC services, which depend both on perception of need and ability to seek and reach care; and intensity of use of PHC, which represents ability to reach and to engage in care. These characteristics, all along the continuum of access to healthcare, belong to the demand-side, whereas the Quebec structural reform mostly affected supply-side aspects such as approachability and availability of services, while setting aside important aspects such as acceptability and appropriateness of services for vulnerable populations [59]. This assessment has been shared by outside observers [61] who felt that the reform addressed supply-side issues but that little was made to raise public awareness to the changes it involved, and that therefore there was no true demand-side pressure from the general public. The demand-side focus in Quebec has been on access to ER and not so much on PHC until recently. Furthermore, though the tendency is to generalize access to multidisciplinary teams, patients may not be ready yet for such a change, and not all patients benefit equally from such an approach [62].

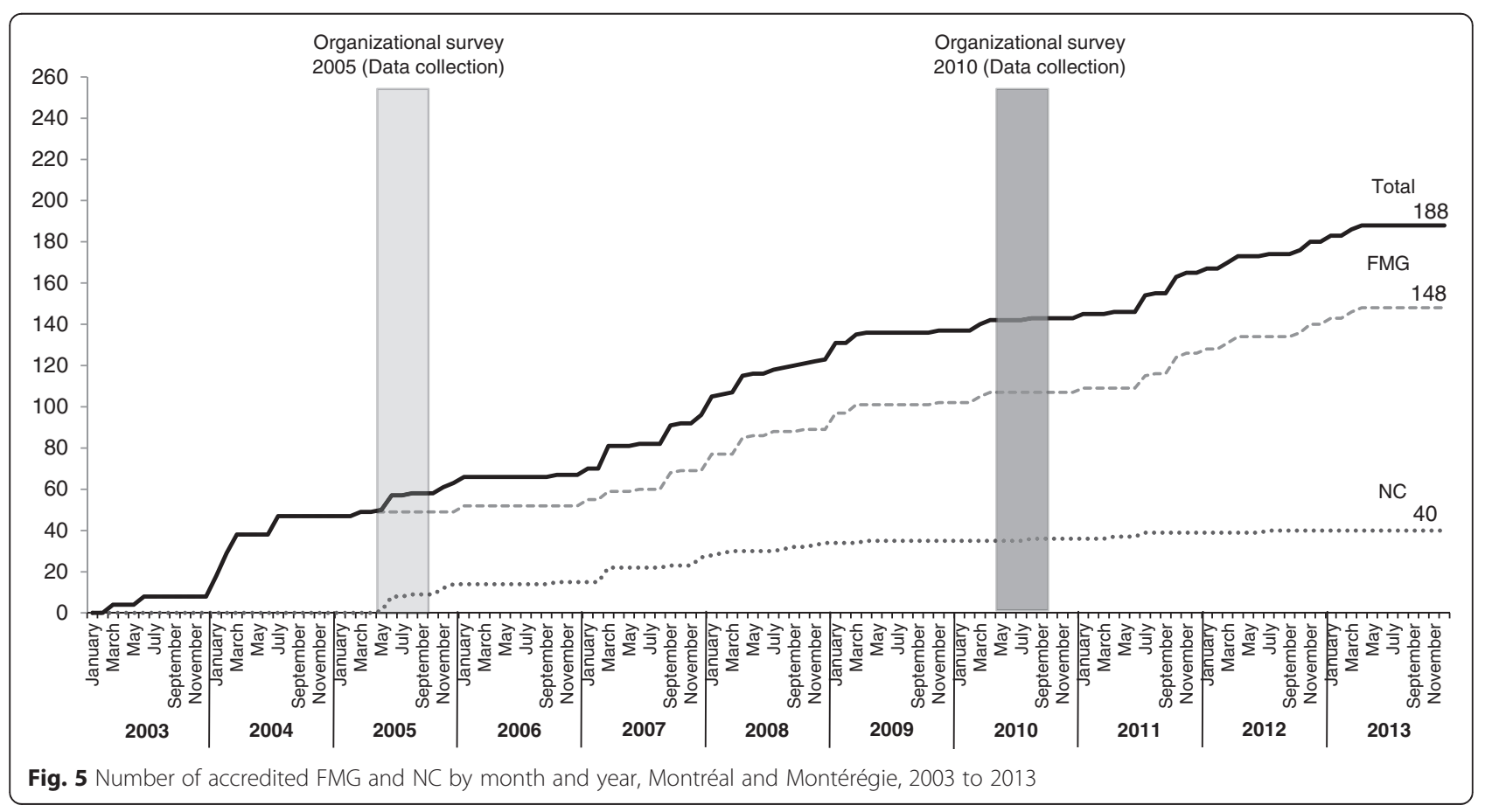




\section{Study limitations}

Our study has some limitations. First of all, as discussed previously, our morbidity measure is only partial and does not take into account the severity of disease which is likely to be worse for lower-income individuals. On the other hand, lower-income people, who have a lower rate of consultation for most preventive services [63], may be less aware of their risk factors than the more advantaged population. Despite these limitations, our index has previously shown to be a good predictor for use of services, as mentioned above.

Also, the survey form of the study leads to the possibility of a recall bias: the perception of an individual's utilization is not as accurate as would be the use of administrative databases, but it is more compatible with a patient-centred perspective. Also, we do not believe that this type of bias should be stronger in one group in particular.

The sample size and relatively good response rates allow us to have confidence in our results. Other surveys of the kind show similar response rates [54]. We do not have information on non-respondents, therefore it is impossible to determine the extent of non-response bias, but this in turn is minimized by the use of weighted samples. Also, although the samples differ in their composition, the fact that we used weighted samples and controlled for major socio-demographic variables minimizes the risk of bias.

The nature of the phenomenon observed led to the natural experiment design of this study. No control group could be used, since the whole population is submitted to changes in the health system. Therefore changes that may have occurred which were not due to the reform could not be controlled for.

Our data goes back to 2010. Between 2010 and 2015, many more FMGs and NCs were created; many clinics therefore lost their group status (Fig. 5). However, we have reason to believe that the situation since 2010 is similar, since most changes that were eventually added to the creation of the new PHC models, such as access registries and registration of patients, were implemented before 2010 .

\section{Conclusions}

Our study has suggested the presence of pro-rich inequity in affiliation to a family doctor and likelihood of visit to PHC services; some of these inequities appear to have increased between 2003 and 2010 despite the PHC reform. Our study has also suggested that, where affiliation to a family doctor is concerned, the older models of PHC may have become more equitable after the reform, but that inequities may have increased within the newer models. More studies will be needed in order to understand the impact of the organizational model of PHC source on equity, but we feel that a structural reform in itself may not be sufficient to address existing inequities.
Demand-side issues should also be addressed by increasing public awareness, thus improving health literacy and the process of care-seeking. As Quebec is entering a new era of reforms and especially of its PHC system once again, lessons can be learned from the previous reform that appears to have failed to improve equity. An equityfocused approach should be central to any future healthcare reform.

\section{Endnotes}

${ }^{1}$ Correlation between education and $\mathrm{ES}=0.34$.

${ }^{2}$ Cardiovascular risk factors: hypertension, diabetes, dyslipidemia.

${ }^{3}$ Chronic diseases: asthma/COPD/other respiratory illness, CAD/heart failure/other cardiac illness, arthritis, stroke.

\section{Additional files}

Additional file 1: Population questionnaire. (PDF $198 \mathrm{~kb}$ )

Additional file 2: Organization questionnaire. (PDF $323 \mathrm{~kb}$ )

\section{Abbreviations}

CAD: Coronary artery disease; Cl: Confidence interval; COPD: Chronic obstructive pulmonary disease; FMG: Family medicine group; FMU: Family medicine teaching unit; GP: General practitioner; HSSC: Health and Social Services Centers; LCSC: Local community services center; LHSSN: Local health and social services network; NC: Network clinic; OECD: Organisation for economic cooperation and development; OR: Odds ratio: PHC: Primary healthcare; SES: Socio-economic status; SES: CIUSSS Centre intégré universitaire de santé et services sociaux.

\section{Competing interests}

All authors declare that they have no competing interests.

\section{Authors' contribution}

MJO contributed substantially to analysis and interpretation of data and drafted the article. RP, AP, SP and JFL all contributed substantially to conception and design, acquisition of data, analysis and interpretation of data, and revised the article critically for important intellectual content. MF contributed substantially to analysis and interpretation of data and revised the article critically for important intellectual content. All authors gave final approval of the version to be published.

\section{Authors' information}

$\mathrm{MJO}$ is a family physician who graduated from University of Montreal in 1997. She also holds a MSc in public health that she completed at University of Montreal in 2007. She works mainly as consulting physician to the Public Health Department of Montreal where she conducts research on access to healthcare for vulnerable populations. She has practised family medicine in a wide range of settings including a clinic specializing for immigrants where she conducted research on screening for refugee claimants in 2006. During her MSc, she published her work on community-based insurance schemes. She is still practising family medicine in a primary care organization and a community organization.

$\mathrm{RP}$ is a physician and holds a PhD in medical care organization from the University of Michigan (Ann Arbor). He was Director of the Department of Social and Preventive Medicine from 1981 to 1992 and Vice Dean of Public Health from 1993 to 1995 for the Faculty of Medicine at University of Montreal. From 1997 to 2001 he was Director of the Health Interdisciplinary Research Group and Deputy Director of the CHUM Research Center. His research interests have more recently focused on the problems of primary care as well as knowledge transfer and dissemination of research results to managers and decision makers. He is the author of numerous scientific 
articles and has directed more than thirty master's and doctorate students. He was named professor emeritus at University of Montreal in September 2003. The Quebec Population Health Research Network in 2006 awarded him the prize for "distinguished scholar". He is currently consulting physician to the Public Health Department of Montreal and the National Public Health Institute of Quebec.

AP completed in 2010 a bi-disciplinary bachelor's degree in demographygeography at University of Montreal. He works as a research assistant at the Public Heath Department of Montreal since 2006. He collaborates mainly on research concerning the organization of health services.

SP is a family physician who graduated from University of Montreal in 1978. She completed a MSc in public health at University of Montreal in 2000. She works as consulting physician to the Public Health Department of Montreal since 2005 where she conducts research on organization of primary health care, utilization of services, chronic diseases and preventive medicine. She has published numerous papers on these subjects. She has been practising in public health since 1986 . She practised family medicine in a wide range of settings from 1979 to 2001.

MF has been a statistician at the Public health department of Montreal since 1998. He completed a bachelor's degree in mathematics in 1990 at University of Montreal; he completed a MSc degree in measurement and evaluation at University of Montreal in 1994.

JFL is a specialist in Public health and preventive medicine and has a PhD in health services research. His research pertains to organisational models of primary care and in the measurement of access to care and performance in health systems. He is currently Chief executive of the Bureau of Health Information, New South Wales, Australia and conjoint professor at the Centre for Primary Health Care and Equity of the University of New South Wales, Australia. He has previously held positions in public health in Quebec province, leading assessment of primary care reforms and reporting on the performance of the provincial system.

\section{Acknowledgements}

All members of the PHHSRG (population health and health services research group).

\section{Author details}

'Direction de la santé publique du CIUSSS du Centre-Sud-de-I'̂le-de-Montréal, 1301 Sherbrooke est, Montréal, Québec H2L 1M3, Canada. ${ }^{2}$ Centre for Primary Health Care and Equity, University of New South Wales, Chatswood, New South Wales, Australia. ${ }^{3}$ Bureau of health information, Level 11, Sage Building, 67 Albert Avenue, Chatswood, New South Wales 2067, Australia.

Received: 13 February 2015 Accepted: 12 October 2015

Published online: 30 November 2015

\section{References}

1. $\mathrm{CSDH}$. Closing the gap in a generation: Health equity through action on the social determinants of health. Final Report of the Commission on Social Determinants of Health. Geneva: World Health Organization; 2008.

2. Van Doorslaer E, Masseria C, Koolman X. Inequalities in access to medical care by income in developed countries. Can Med Assoc J. 2006;174(2):177-83.

3. Crespo-Cebada E, Urbanos-Garrido RM. Equity and equality in the use of GP services for elderly people: The Spanish case. Health Policy. 2012;104(2):193-9.

4. Zhong $\mathrm{H}$. On decomposing the inequality and inequity change in health care utilization: Change in means, or change in the distributions? Int J Healthc Fin Econ. 2010;10(4):369-86.

5. Asada $Y$, Kephart G. Equity in health services use and intensity of use in Canada. BMC Health Serv Res. 2007;7:41.

6. Allin S. Does equity in healthcare use vary across Canadian provinces? Healthc Policy. 2008;3(4):83-99.

7. Birch S, Eyles J, Newbold KB. Equitable access to health care: methodological extensions to the analysis of physician utilization in Canada. Health Econ. 1993;2(2):87-101

8. Whitehead M. The concepts and principles of equity and health. Int J Health Serv. 1992;22(3):429-45.

9. Frohlich $K$, De Koninck $M$, Demers A, Bernard P. Les inégalités sociales de santé au Québec. Montréal: Presses de l'Université de Montréal; 2008.

10. Braveman P. What are health disparities and health equity? We need to be clear. Public Health Rep. 2014;129 Suppl 2:5-8.
11. Bago d'Uva T, Jones AM, van Doorslaer E. Measurement of horizontal inequity in health care utilisation using European panel data. J Health Econ. 2009;28(2):280-9.

12. Hanratty B, Zhang T, Whitehead M. How close have universal health systems come to achieving equity in use of curative services? A systematic review. Int J Health Serv. 2007;37(1):89-109.

13. Starfield B. The hidden inequity in health care. Int J Eq Health. 2011;10:15.

14. Levesque JF, Harris MF, Russell G. Patient-centred access to health care: Conceptualising access at the interface of health systems and populations. Int J Eq Health. 2013;12:18.

15. Haggerty JL, Levesque JF, Santor DA, Burge F, Beaulieu C, Bouharaoui F, et al. Accessibility from the patient perspective: Comparison of primary healthcare evaluation instruments. Healthc Policy. 2011;7(Spec Issue):94-107.

16. Pineault R. Comprendre le système de santé pour mieux le gérer. Montréal: Presses de l'Université de Montréal; 2012.

17. Gouvernement du Québec. The Québec health and social services system: In brief. Ministère de la Santé et des Services sociaux: Québec; 2008.

18. Pomey MP, Martin E, Forest PG. Quebec's Family Medicine Groups: Innovation and compromise in the reform of front-line care. Can Pol Sc Rev. 2009:3(4):31-46

19. Breton M, Levesque JF, Pineault $R$, Hogg W. Primary care reform: Can Quebec's Family Medicine Group Model benefit from the experience of Ontario's Family Health Teams? Healthc Policy. 2011;7(2):e122-35.

20. Gouvernement du Québec. Projet de loi no 25: Loi sur les agences développement de réseaux locaux de services de santé et de services sociaux. MSSS: Québec; 2003.

21. Le Blanc MF, Raynault MF. Les inégalités sociales de santé à Montréal: Le chemin parcouru. Montréal: Direction de santé publique de l'Agence de la santé et des services sociaux de Montréal; 2011.

22. Jesmin S, Thind A, Sarma S. Does team-based primary health care improve patients' perception of outcomes? Evidence from the 2007-08 Canadian survey of experiences with primary health. Health Policy. 2012;105(1):71-83.

23. Beaulieu MD, Denis JL, D'Amour D, Goudreau J, Haggerty J, Hudon E, et al. Implementing family medicine groups: The challenge in the reorganization of practice and interprofessional collaboration - Case study of five FMGs in the first wave of Québec FMGs. Montréal: Doctor Sadok Besrour Chair, Université de Montréal; 2006.

24. Levesque JF, Pineault R, Roberge D, Kapetanakis C, Simard B, Prud'homme A. Emerging organisational models of primary healthcare and unmet needs for care: Insights from a population-based survey in Quebec province. BMC Fam Pract. 2012;13(1):66.

25. Tan S, Mays N. Impact of initiatives to improve access to, and choice of, primary and urgent care in the England: A systematic review. Health Policy. 2014;118:304-15.

26. Levesque JF, Pineault $R$, Provost $S$, Tousignant $P$, Couture $A$, Borgès Da Silva $R$, et al. Assessing the evolution of primary healthcare organizations and their performance (2005-2010) in two regions of Québec province: Montréal and Montérégie. BMC Fam Pract. 2010;11(1):95-107.

27. Lemoine $\mathrm{O}$, Simard $B$, Provost $\mathrm{S}$, Levesque JF, Pineault $R$, Tousignant $P$. Rapport méthodologique de l'enquête populationnelle sur l'expérience de soins à Montréal et en Montérégie. Montreal: Direction de santé publique de l'Agence de la santé et des services sociaux de Montréal et Institut National de santé publique du Québec; 2011.

28. Prud'homme A, Pineault $R$, Couture A, Borgès da Silva $R$, Levesque JF, Tousignant P. Rapport méthodologique de l'enquête organisationnelle à Montréal et en Montérégie. Montreal: Direction de santé publique de l'Agence de la santé et des services sociaux de Montréal et Institut National de santé publique du Québec; 2012.

29. Couture A, Pineault R, Prud'homme A, Provost S, Borgès Da Silva R, Levesque JF, et al. Rapport descriptif de l'enquête organisationnelle pour la région de la Montérégie. Montréal: Direction de santé publique de l'Agence de la santé et des services sociaux de Montréal et Institut national de santé publique du Québec; 2012.

30. Pineault $\mathrm{R}$, Couture A, Prud'homme A, Provost $\mathrm{S}$, Borges da Silva $\mathrm{R}$ Levesque JF, et al. Rapport descriptif de l'enquêteorganisationnelle pour la région de Montréal. Montréal: Direction de santé publique de l'Agence de la santé et des services sociaux de Montréal et Institut national de santé publique du Québec; 2012

31. Lemoine $O$, Simard B, Provost $S$, Levesque JF, Pineault $R$, Tousignant $P$. Rapport descriptif de l'enquête populationnelle sur l'expérience de soins à Montréal et en Montérégie. Montréal: Direction de santé publique de I'Agence de la santé et des services sociaux de Montréal et Institut national de santé publique du Québec; 2011. 
32. Pineault $R$, Borgès Da Silva $R$, Prud'homme A, Fournier $M$, Couture $A$, Provost $S$, et al. Impact of Québec's healthcare reform on the organization of primary healthcare (PHC): A 2003-2010 follow-up. BMC Health Serv Res. 2014;14:229.

33. Starfield B. Primary care: Balancing health needs, services and technology. New York: Oxford University Press; 1998

34. Nowatzki NR. Wealth inequality and health: A political economy perspective. Int J Pub Health. 2012;42(3):403-24.

35. Carr-Hill R, Chalmers-Dixon P. The Public Health Observatory Handbook of health inequalities measurement. Oxford: South East Public Health Observatory; 2005.

36. Institut de la statistique du Québec. Santé et bien-être, immigrants récents au Québec: Une adaptation réciproque? Étude auprès des communautés culturelles 1998-1999. Québec: Institut de la statistique du Québec; 2002.

37. Diamantopoulos A, Winklhofer HM. Index construction with formative indicators: An alternative to scale development. J Mark Res. 2001;38(2):269-77.

38. Diamantopoulos A, Siguaw JA. Formative versus reflective indicators in organizational measure development: A comparison and empirical illustration. Br J Man. 2006;17(4):263-82.

39. Diamantopoulos A, Riefler $P$, Roth KP. Advancing formative measurement models. J Bus Res. 2008;61(12):1203-18.

40. Bollen KA, Bauldry S. Three Cs in measurement models: Causal indicators, composite indicators, and covariates. Psychol Methods. 2011;16(3):265-84.

41. Bollen KA. Evaluating effect, composite, and causal indicators in structural equation models. MIS Q. 2011;35(2):359-72.

42. Stewart J. Economic status (http://www.macses.ucsf.edu/research/socialenviron/ economic.php). Accessed on 2 Feb 2015

43. Pineault $R$, Tousignant $P$, Provost $S$, Borgès Da Silva R, Prud'homme A, Fournier $M$, et al. Évolution de l'organisation, de l'expérience de soins et de l'utilisation des services de santé de $1^{\text {re }}$ ligne (2003-2010) à Montréal et en Montérégie. Rencontre du comité consultatif, 27 mars 2014. Montréal: Direction de santé publique de l'Agence de la santé et des services sociaux de Montréal et Institut national de santé publique du Québec; 2014.

44. Andersen RM. Revisiting the behavioral model and access to medical care: Does it matter? J Health Soc Beh. 1995;36(March):1-10

45. Andersen RM, Newman JF. Societal and individual determinants of medical care utilization in the United States. Milbank Q. 2005;83(4):1-28.

46. Baron RM, Kenny DA. The moderator-mediator variable distinction in social psychological research: Conceptual, strategic, and statistical considerations. J Pers Soc Psy. 1986;51(6):1173-82.

47. Luciano JV, Fernandez A, Pinto-Meza A, Lujan L, Bellon JA, Garcia-Campayo $J$, et al. Frequent attendance in primary care: Comparison and implications of different definitions. Brit J Gen Pract. 2010;60(571):49-55.

48. Parejo MN, Lendínez-de la Cruz JM, Bermúdez-Torres FM, Gónzalez-Contero L, Gutierrez-Espinosa de Los Monteros MP, Espejo-Almazán María T. [Prevalence and factors associated with frequent attendence in family medicine clinic]. Semergen 2015. doi:10.1016/j.semerg.2015.05.011. [Epub ahead of print].

49. Smits FT, Brouwer HJ, ter Riet G, van Weert HC. Epidemiology of frequent attenders: a 3-year historic cohort study comparing attendance, morbidity and prescriptions of one-year and persistent frequent attenders. BMC Public Health 2009, 9(36). doi:10.1186/1471-2458-9-36.

50. $\mathrm{ClH}$. Hospitalization disparities by socio-economic status for males and females. Ottawa: Canadian Institute for Health Information (CIHI); 2010.

51. Lemstra M, Mackenbach J, Neudorf C, Nannapaneni U. High health care utilization and costs associated with lower socio-economic status: Results from a linked dataset. Can J Pub Health. 2009;100(3):180-3.

52. Glazier RH, Agha MM, Moineddin R, Sibley LM. Universal health insurance and equity in primary care and specialist office visits: A population-based study. Ann Fam Med. 2009;7(5):396-405.

53. Mclsaac W, Goel V, Naylor D. Socio-economic status and visits to physicians by adults in Ontario, Canada. J Health Serv Res Policy. 1997;2(2):94-102.

54. McGrail KM, van Doorslaer E, Ross NA, Sanmartin C. Income-related health inequalities in Canada and the United States: a decomposition analysis. Am J Public Health. 2009:99(3):1-8.

55. Giovanella L, Stegmüller K. The financial crisis and health care systems in Europe: universal care under threat? Trends in health sector reforms in Germany, the United Kingdom, and Spain. Cad Saud Publica. 2014;30(11):2263-81.

56. Laditka JN, Laditka SB, Probst JC. More may be better: Evidence of a negative relationship between physician supply and hospitalization for ambulatory care sensitive conditions. Health Serv Res. 2005;40(4):1148-66.

57. Ansari Z, Laditka JN, Laditka SB. Access to health care and hospitalization for ambulatory care sensitive conditions. Med Care Res Rev. 2006;63(6):719-41.
58. Zenklusen S, Bischoff T, Panese F, Bodenmann P. Compétences en santé déficientes: Obstacle à une prise en charge optimale. Rev Med Suisse. 2012;8:1016-21.

59. Loignon C, Hudon C, Goulet E, Boyer S, De Laat M, Fournier N, et al. Perceived barriers to healthcare for persons living in poverty in Quebec, Canada: the EQUIhealThy project. Int J Eq Health. 2015;14:4.

60. Gouvernement du Québec: Report of the Auditor general of Québec to the National Assembly for 2015-2016. Chapter 5. Available from: http:// www.vgq.qc.ca/en/en_publications/en_rapport-annuel/en_fichiers/ en_Rapport2015-2016-VOR-Printemps.pdf. Accessed on 19 Aug 2015..

61. Forget CE. The case of the vanishing Québec physicians: how to improve access to care. Healthcare Policy 2014, commentary no 410. doi:10.2139/ ssrn.2442524.

62. Chan WS, Whitford DL, Conroy R, Gibney D, Hollywood B. A multidisciplinary primary care team consultation in a socio-economically deprived community: an exploratory randomised controlled trial. BMC Health Serv Res 2011, 11(15). doi:10.1186/1472-6963-11-15.

63. Simoneau ME, Ouimet MJ. L'exposition aux pratiques cliniques préventives. Série I'Observateur. Montréal: Direction de santé publique du CIUSSS du Centre-sud-de-l'île-de-Montréal; 2015.

\section{Submit your next manuscript to BioMed Central and take full advantage of:}

- Convenient online submission

- Thorough peer review

- No space constraints or color figure charges

- Immediate publication on acceptance

- Inclusion in PubMed, CAS, Scopus and Google Scholar

- Research which is freely available for redistribution 